\title{
Antibodies to Opacity Proteins (Opa) Correlate with a Reduced Risk of Gonococcal Salpingitis
}

\author{
Francis A. Plummer, ${ }^{\star 8}$ Hilary Chubb," J. Neil Simonsen," Milcha Bosire,” Leslie Slaney, ${ }^{\star}$ Nico J. D. Nagelkerke," \\ Ian Maclean, ${ }^{*}$ Jackoniah O. Ndinya-Achola, ${ }^{*}$ Peter Waiyaki, ${ }^{*}$ and Robert C. Brunham ${ }^{\star}$ \\ *Departments of Medical Microbiology, Medicine, and Community Health Sciences, University of Manitoba, Winnipeg, Manitoba \\ R3E 0W3, Canada; ${ }^{\ddagger}$ Centre for Microbiology Research, Kenya Medical Research Institute, Nairobi, \\ and ${ }^{\S}$ Department of Medical Microbiology, University of Nairobi, Nairobi, Kenya
}

\begin{abstract}
Acute salpingitis complicating cervical gonococcal infection is a significant cause of infertility. Relatively little data are available concerning the pathophysiologic mechanisms of this disease. A cohort of 243 prostitutes residing in Nairobi were followed between March 1985 and April 1988. Gonococcal cultures were performed at each visit, and acute salpingitis was diagnosed clinically. Serum at enrollment was tested by immunoblot for antibody to gonococcal outer membrane proteins. $8.6 \%(146 / 1689)$ of gonococcal infections were complicated by salpingitis. Increased risk of salpingitis was associated with younger age, shorter duration of prostitution, HIV infection, number of gonococcal infections, and episodes of nongonococcal salpingitis. Rmp antibody increased the risk of salpingitis. Antibody to Opa decreased the risk of salpingitis. By logistic regression analysis, antibody to Opa was independently associated with decreased risk of gonococcal salpingitis (adjusted odds ratio [OR], 0.35; 95\% confidence interval [95\%CI], 0.170.76); HIV infection (adjusted OR, 3.5; 95\% CI, 0.96-12.8) and episodes of nongonococcal salpingitis (adjusted OR, 3.4; 95\% CI, 1.8-6.4) were independently associated with an increased risk of salpingitis. Antibody to Opa appears to protect against ascending gonococcal infection, perhaps by interfering with Opa mediated adherence and endocytosis. The demonstration of natural immunity that protects against upper genital tract infection in women suggests that a vaccine to prevent gonococcal salpingitis is possible. (J. Clin. Invest. 1994. 93:17481755). Key words: Neisseria gonorrhoeae - gonococcal immunity $\bullet$ protein II $\bullet$ pelvic inflammatory disease $\bullet$ cervicitis
\end{abstract}

\section{Introduction}

One of the principal reasons for the importance of Neisseria gonorrhoeae as a health concern is its adverse impact on the reproductive health of women. Both mathematical models and empirical data suggest that gonococcal infections exert a strong influence on human population growth (1), particularly in de-

Address correspondence to Dr. F. A. Plummer, Department of Medical Microbiology, University of Manitoba, Room 514, 730 William Avenue, Winnepeg, Manitoba R3E 0W3, Canada.

Received for publication 10 November 1993 and in revised form 22 December 1993.

J. Clin. Invest.

(c) The American Society for Clinical Investigation, Inc.

0021-9738/94/04/1748/08 \$2.00

Volume 93, April 1994, 1748-1755 veloping countries. In sub-Saharan Africa 5-10\% of asymptomatic healthy women have gonococcal cervicitis (2). A woman with a gonococcal cervicitis is at high risk of developing ascending infection, acute salpingitis, and its subsequent complications. The frequency of salpingitis during gonococcal infection is thought to be between 8 and 10\% (3). Fallopian tube infection commonly results in scarring with consequent infertility; $15-40 \%$ of women develop tubal scarring after an episode of salpingitis (3). Ectopic tubal pregnancy, with its risk of death, is another severe consequence of acute salpingitis. The overall frequency of ectopic pregnancy after an episode of acute salpingitis is unknown, but the contribution of ectopic pregnancy to maternal mortality worldwide is considerable (4).

The pathogenesis of gonococcal salpingitis is incompletely understood. Factors that increase exposure, the risk of infection, and the likelihood of salpingitis in the event of a gonococcal infection are all steps in the causal pathway of gonococcal salpingitis (5). A variety of risk factors that operate at discrete steps in the causal pathway have been described. Some risk factors operate at multiple steps in the causal pathway but not necessarily in the same direction. Certain organism or host factors such as gonococcal strain characteristics (6), younger age, race, the stage in the menstrual cycle, wearing an intrauterine contraceptive device, and practices such as vaginal douching (7) have been associated with higher risk of acute salpingitis. Other factors, such as hormonal contraception, have been associated with a reduced risk of gonococcal salpingitis (8). Most of these described risk factors for gonococcal salpingitis operate on the exposure or infection steps. For instance, sexual behaviour and possibly ethnicity act through increasing exposure rather than involvement in the pathogenesis of salpingitis. Overall, we have very little understanding of why one woman develops acute gonococcal salpingitis while another has an uncomplicated course of infection.

Understanding the pathogenesis of gonococcal salpingitis and potential immune defence mechanisms could lead to new strategies that prevent this disease. There has been only one study of how immunity affects the likelihood of salpingitis during gonococcal infection. In this study, of 9 women reinfected with a strain of the same Por type, none developed salpingitis, whereas 5 of 10 women reinfected with a different Por type developed salpingitis (9). However, this study did not control for Por prevalence and did not consider the effect of other surface components of the gonococcus. With the objectives of understanding the role of host immune factors in gonococcal infection and disease, we established an open cohort study of $N$. gonorrhoeae epidemiology and immunity among a community of prostitutes in Nairobi in 1985. Analysis of risk factors for gonococcal infection have been previously reported $(10$, 11). Rmp antibody increased the risk of gonococcal infection 
while antibody to Por and Opa had no discernible effect on the occurrence of gonococcal infection. Here we report on the risk factors for gonococcal salpingitis, including the effect of antibody to gonococcal outer membrane protein antigens, among 243 women enrolled in this study who had at least one episode of gonococcal infection.

\section{Methods}

Study design and patient population. 243 women working as prostitutes in a slum area of Nairobi were enrolled in a study of gonococcal epidemiology in 1985. These women are part of a large open cohort study of sexually transmitted disease epidemiology and prevention which has been described extensively elsewhere $(10,11)$. Women were followed at 2-4 wk intervals between March 1985 and July 1988.

Enrollment and follow-up of women have been previously described $(10,11)$. Briefly, demographic, sexual, reproductive, and medical histories were obtained in a standard format interview, and complete physical examinations, including vaginal speculum and bimanual examinations, were performed at enrollment. Specimens for culture of $N$. gonorrhoeae and for serology for HIV and gonococcal immunoblot were obtained. Women were scheduled for follow-up at 2-wk intervals. At each visit, interval symptoms were reviewed, a genital examination was performed, and endocervical swabs for gonococcal culture were obtained. All women returned to the clinic 3-4 d later for results, at which time treatment for positive cultures was administered. $4 \mathrm{~d}$ after treatment, a test of cure culture was performed.

Laboratory methods. Specimens for $N$. gonorrhoeae culture were immediately inoculated on modified Thayer-Martin media, transported to the laboratory within $3 \mathrm{~h}$, and incubated at $37^{\circ} \mathrm{C}$ for $48 \mathrm{~h} . N$. gonorrhoeae was identified by colony morphology, Gram stain, and oxidase reactivity, and later confirmed by determination of nutritional requirements. Cultures were stocked frozen in skim milk with $10 \%$ glycerol for later serotyping. Por serovar determinations were performed using the monoclonal antibody typing system of Knapp et al. (12).

Five Por serovars (1B1, 1B3, 1B5, 1A4, and 1A6) comprised $81 \%$ of the serovars in the population. The potential role of outer membrane protein antibody in mediating resistance to gonococcal infection was assessed by determining the frequency of serum antibody at enrollment to the three principal outer membrane proteins (Por, Opa, and Rmp) of these five Por serovars circulating in the population by immunoblot. Standardized whole-cell preparations of 18-h cultures of each serovar were solubilized by boiling in SDS and 2-mercaptoethanol. Antigens for each serovar were prepared in a single large batch and frozen in aliquots for later use. Subsequently, antigen preparations were separated by SDS-PAGE on $12.5 \%$ gels (13) and transferred to Immobilon P, PVDF membranes (Millipore Corp., Bedford, MA) by electroblotting (14). To remove potential cross reacting antibody specific for other organisms, sera were preabsorbed with $100 \mu \mathrm{g}$ each of whole cell preparations of $N$. sicca, $N$. meningitidis, $N$. lactamica, Haemophilus influenzae, $H$. ducreyi, and $H$. parainfluenzae at $4^{\circ} \mathrm{C}$ overnight followed by centrifugation to remove the organisms. Membranes were preblocked with a 5\% skim milk in Tris-buffered saline and incubated with absorbed sera overnight at $4^{\circ} \mathrm{C}$. Immunostaining followed standard protocols using goat anti-human IgG conjugated to horseradish peroxidase (Jackson Immunoresearch Laboratories Inc., West Grove, PA) and diaminobenzidine with cobalt chloride (Sigma Chemical Co., St. Louis, MO) (15). Biotinylated and prestained molecular weight standards (Bio-Rad Laboratories, Richmond, CA) were included on the blots. Blots were read visually by an observer blinded to the results of clinical and epidemiologic studies. Molecular weight standards and monoclonal antibody, all Opa specific (donated by Dr. Milan Blake, The Rockefeller University, New York), were used to determine the antibody specificity of antigen antibody reactions. To confirm the heatmodifiable nature of proteins identified as Opa by immunoblotting, PAGE gels were also run at $37^{\circ} \mathrm{C}$ and $56^{\circ} \mathrm{C}$. The first available serum from each of the 243 study women was tested in this assay. Only observations recorded after the date of serum collection were analyzed. Antibody to the three principal gonococcal outer membrane proteins was then correlated to the subsequent occurrence of infection and salpingitis.

Definitions and data analysis. Because we were interested in examining risk factors for gonococcal salpingitis, the analysis was limited to women who had at least one gonococcal infection. All diagnoses of acute salpingitis were clinical. The following criteria were used to make a diagnosis of salpingitis. During bimanual examination, cervical motion tenderness and fallopian tube tenderness were scored from 0 to 4 : 0 , no tenderness; 1 , complaints of tenderness; 2 , objective signs of tenderness such as guarding; 3 , severe tenderness; 4 , peritoneal signs. Salpingitis was diagnosed if the score for tubal or cervical motion tenderness was $\geq 2$. Salpingitis was ascribed to $N$. gonorrhoeae if the endocervical culture was positive. No attempt was made to diagnosis other causes of salpingitis. Subsequent episodes of salpingitis were defined as new episodes if $>4 \mathrm{wk}$, during which the woman was asymptomatic, intervened between episodes. Otherwise, they were considered to be a single episode.

Demographic and clinical parameters and the frequency of outer membrane protein antibodies were correlated with the frequency of gonococcal infection. Relative risks with $95 \%$ confidence intervals, $\chi^{2}$ tests, students's $t$ test, and one way analysis of variance were used to compare risks, proportions, and means (16). Logistic regression was used to perform multivariate analysis. For multivariate analysis of the occurrence of multiple episodes of salpingitis, we used the following approach. The distribution of the number of episodes of salpingitis was assumed to be binomial, with parameters $P_{1}$ (the proportion of gonococcal infections with salpingitis) and $n$ (the number of gonococcal cultures) (16). For $P_{1}$, the logistic model: $\log \left(P_{\mathrm{i}} / 1-P_{\mathrm{i}}\right)=\beta_{0}+\beta_{1} X_{1}$ $+\beta_{2} X_{2} \ldots$. ) was assumed and fitted to the data using the generalized linear interactive modelling (GLIM) program. The scale GLIM directive was used to allow for extra-binomial variance.

\section{Results}

The 243 study subjects were followed for 1-38 mo (March 1985 through April 1988). There were a total of 3,616 study visits (mean, 14.9 \pm 11.6 ), and 1,689 gonococcal infections (mean, 7.0 \pm 5.9 ) occurred. All women had a least one episode of cervical gonococcal infection. 85 women experienced 146 episodes of gonococcal salpingitis $(8.6 \%$ of all gonococcal infections). There were 97 episodes of nongonococcal salpingitis. Initially, 167 women were HIV seropositive $(68.7 \%)$; 54 women seroconverted to HIV during follow-up. Very few women used condoms in the first months of the study but this changed rapidly after June 1986 (17). Douching after sex, most commonly with soap and water, was universally practiced (data not shown).

Risk factors for gonococcal salpingitis are analyzed in Table I. Compared with women with cervical gonococcal infection, women with one or more episode of gonococcal salpingitis were younger, reported a shorter duration of prostitution, more frequently used antibiotics prophylactically (most commonly tetracycline), had more gonococcal infections, more frequently had episodes of nongonococcal salpingitis, and were more frequently HIV positive. There was no relationship between the number of sex partners per day, oral contraceptive use, condom use, and gonococcal salpingitis. Too few women used other methods of contraception for meaningful analysis.

In Fig. $1 a$, a Coomassie blue-stained polyacrylamide gel of outer membrane preparations shows the outer membrane proteins of the five Por serovar panel. A representative immunoblot of the panel tested with absorbed sera is shown in Fig. $1 b$. 


\begin{tabular}{|c|c|c|c|}
\hline & $\begin{array}{l}\text { Gonococcal } \\
\text { salpingitis } \\
(n=85)\end{array}$ & $\begin{array}{l}\text { Gonococcal } \\
\text { cervicitis } \\
(n=158)\end{array}$ & $P$ \\
\hline Age (mean yr $\pm \mathrm{SD}$ ) & $27.9 \pm 5.6$ & $30.1 \pm 5.9$ & $<0.005$ \\
\hline Duration of prostitution (mean mo \pm SD) & $35.5 \pm 34.3$ & $47.1 \pm 47.3$ & $<0.05$ \\
\hline Sex partners per day (mean \pm SD) & $3.8 \pm 2.3$ & $3.8 \pm 2.1$ & 0.95 \\
\hline Using antibiotic prophylaxis & $11(12.9)$ & $31(19.6)$ & $\begin{array}{l}0.2 ; \mathrm{RR}, 0.71 ; \\
\quad 95 \% \text { CI, } 0.42-1.2\end{array}$ \\
\hline Using oral contraceptives & $22(25.8)$ & $43(27.2)$ & $\begin{array}{l}0.82 ; \mathrm{RR}, 0.96 ; \\
95 \% \text { CI, 0.66-1.4 }\end{array}$ \\
\hline Condom use $>50 \%$ of intercourse & $7(8.2)$ & $20(12.7)$ & $\begin{array}{l}0.3 ; \text { RR, 0.72; } \\
\quad 95 \% \text { CI, 0.37-1.4 }\end{array}$ \\
\hline Proportion of gonococcal cultures positive & $0.52 \pm 0.16$ & $0.52 \pm 0.24$ & 0.54 \\
\hline HIV negative & $3(3.5)$ & $19(12.0)$ & \\
\hline Initially HIV seropositive & $60(70.6)$ & $107(67.7)$ & $\begin{array}{l}<0.03 ;{ }^{*} \mathrm{RR}, 2.7 ; \\
\quad 95 \% \text { CI, 0.94-7.9 }\end{array}$ \\
\hline Seroconverted to HIV during study period & $22(25.8)$ & $32(20.2)$ & \\
\hline
\end{tabular}

Numbers in parentheses are percent.

${ }^{*}$ HIV-seropositive and seroconverting women are compared with HIV-negative women.

$41 \%$ of women tested had Rmp antibody. Antibody to one or more Por was detected in $92 \%$ of women. Antibody to one or more Opa molecular variants was detected in $92 \%$ of women. There was a direct relationship between the frequency of Por antibody and Rmp antibody; the mean of the number of antibodies to Por variants was $3.7 \pm 1.8$ among women with no antibody to $\mathrm{Rmp}$ compared with $4.3 \pm 1.2$ to women with antibody to $\operatorname{Rmp}(P<0.005, t$ test $)$. Antibody to Opa variants did not correlate with Por or Rmp antibody. There was no apparent association of antibody to Por and gonococcal salpingitis. The frequency of Rmp antibody was greater among women with gonococcal salpingitis, although the increase in risk was modest (relative risk $[R R]=1.7 ; 95 \%$ confidence interval $[\mathrm{CI}]$, 1.04-1.88; $P<0.05)^{1}$

Nine Opa molecular weight variants were expressed by the five Por serovars. Although there were two pairs with similar molecular weights, as estimated by PAGE, they appeared to differ antigenically; individuals who reacted to one did not necessarily react with the other. The number of antibody to the nine Opa variants is compared to the risk of gonococcal salpingitis in Table II. Women with one or more episodes of gonococcal salpingitis had antibody to fewer Opa variants than women with gonococcal infection but no salpingitis $\left(\chi^{2}\right.$ test for trend, $P$ $<0.01$ ).

To explore the relationship between Opa antibody and gonococcal salpingitis, we compared the frequency of antibody to the nine Opa variants with the occurrence of gonococcal salpingitis. The occurrence of one or more episodes of gonococcal salpingitis, the proportion of gonococcal infections resulting in salpingitis, and the risk of recurrent gonococcal salpingitis were compared among women with antibody to $0-3,4-6$, and 7-9 Opa variants. The proportion of women with one or more episodes of gonococcal salpingitis and the relative risk of one or more episodes of gonococcal salpingitis in relation to

1. Abbreviations used in this paper: $\mathrm{CI}$, confidence interval; OR, odds ratio; $R R$, relative risk.
Opa antibody are shown in Fig. $2.43 \%$ of women with antibody to 0-3 Opa variants had an episode of gonococcal salpingitis compared with 35 and $21 \%$ of women with 4-6 and 7-9 Opa variants, respectively. The relative risk for one or more episodes of gonococcal salpingitis was 0.80 (95\% CI, 0.56-1.15) and 0.48 (95\% CI, 0.27-0.83) for 4-6 and 7-9 antibodies to Opa variants compared with $0-3$ antibodies to Opa variants. a

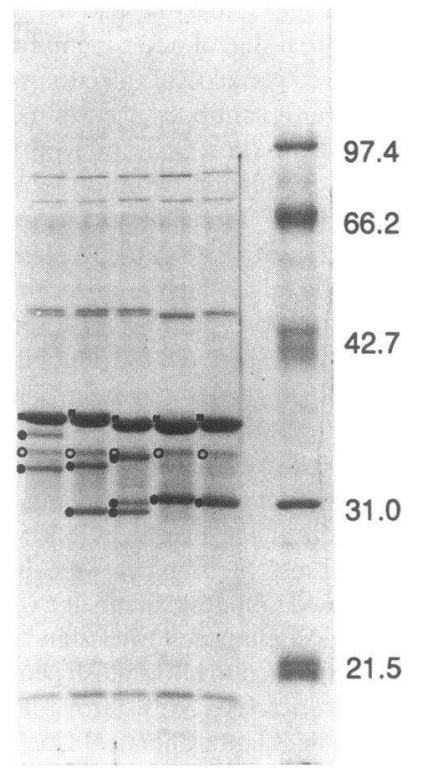

b

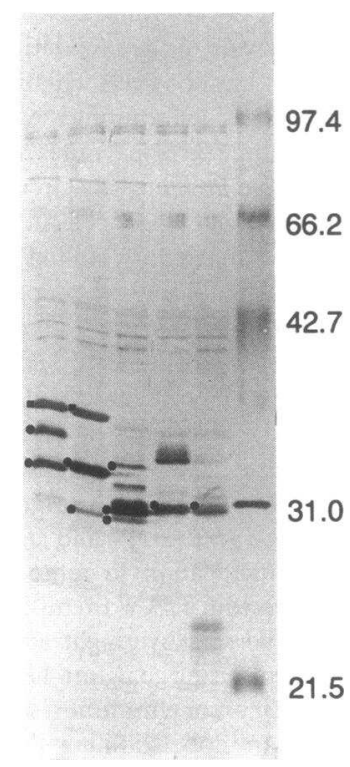

Figure 1. (a) Coomassie blue-stained polyacrylamide gel of outer membrane preparations of the five Por serovar panel. Lane 1, 1B-1; lane 2, 1B-3; lane 3,1B-5; lane 4, 1A-4; lane 5, 1A-6; and lane 6, molecular weight standards. Filled squares indicate Por, filled circles indicate Opa, and open circles indicate $\mathrm{Rmp}$. (b) A representative immunoblot of the reactivity of absorbed serum with whole cell preparations of the five Por serovar panel. Antibody to Rmp is absent. Filled squares indicate Por, and closed circles indicate Opa. 


\begin{tabular}{|c|c|c|c|c|c|}
\hline & & & $\begin{array}{l}\text { Gonococcal } \\
\text { salpingitis } \\
(n=85)\end{array}$ & $\begin{array}{l}\text { Gonococcal } \\
\text { cervicitis } \\
(n=158)\end{array}$ & $P$ \\
\hline \multirow{6}{*}{$\begin{array}{l}\text { No. of antibody to } \\
\text { Opa variants }\end{array}$} & \multicolumn{2}{|r|}{ Any } & $77(90.6)$ & $146(92.4)$ & $0.62 ; \mathrm{RR}, 0.87$ \\
\hline & \multicolumn{2}{|r|}{$0-3$} & $43(506)$ & $56(354)$ & \\
\hline & \multirow{2}{*}{\multicolumn{2}{|c|}{$4-6$}} & $30(353)$ & $56(354)$ & $0005 \gamma^{2}$ test for \\
\hline & & & & & trend \\
\hline & \multicolumn{2}{|r|}{$7-9$} & $12(14.1)$ & $46(29.1)$ & \\
\hline & Serovar & Molecular mass & & & \\
\hline \multirow{9}{*}{$\begin{array}{l}\text { Antibody to } \\
\text { specific Opa } \\
\text { variants }\end{array}$} & 1B-1 & $34.5^{\ddagger}$ & $28(32.9)$ & $69(44.8)$ & $\begin{array}{l}0.14 ; \mathrm{RR}, 0.74 \\
\quad 95 \% \text { CI, 0.51-1.1 }\end{array}$ \\
\hline & 1B-1 & 32.5 & $25(29.4)$ & $65(38.0)$ & $\begin{array}{l}0.23 ; \mathrm{RR}, 0.73 \\
\quad 95 \% \mathrm{CI}, 0.5-1.1\end{array}$ \\
\hline & 1B-3 & 32.8 & $43(50.5)$ & $97(61.4)$ & $\begin{array}{l}0.14 ; \mathrm{RR}, 0.75 \\
\quad 95 \% \text { CI, 0.54-1.1 }\end{array}$ \\
\hline & 1B-3 & 29.8 & $40(47.1)$ & $97(60.1)$ & $\begin{array}{l}0.07 ; \text { RR, 0.71; } \\
\quad 95 \% \text { CI, 0.5-1.0 }\end{array}$ \\
\hline & 1B-5 & 33.5 & $12(14.1)$ & $23(14.6)$ & $\begin{array}{l}1.0 ; \mathrm{RR}, 0.98 \\
95 \% \mathrm{CI}, 0.6-1.6\end{array}$ \\
\hline & 1B-5 & 30.0 & $25(29.4)$ & $75(47.4)$ & $\begin{array}{l}<0.01 ; \text { RR, } 0.6 ; \\
\quad 95 \% \text { CI, 0.4-0.88 }\end{array}$ \\
\hline & $1 B-5$ & 29.8 & $41(48.2)$ & $82(51.9)$ & $\begin{array}{l}0.68 ; \mathrm{RR}, 0.91 ; \\
95 \% \text { CI, } 0.65-1.3\end{array}$ \\
\hline & $1 \mathrm{~A}-4$ & 30.5 & $41(60.0)$ & $104(65.8)$ & $\begin{array}{l}0.45 ; \mathrm{RR}, 0.85 ; \\
95 \% \text { CI, 0.85-1.2 }\end{array}$ \\
\hline & $1 \mathrm{~A}-6$ & 30.5 & $48(56.5)$ & $118(74.7)$ & $\begin{array}{l}<0.01 ; \text { RR, 0.6; } \\
\quad 95 \% \text { CI, 0.43-0.83 }\end{array}$ \\
\hline
\end{tabular}

Numbers in parentheses are percent. ${ }^{\ddagger}$ Data are in kilodaltons.

We also examined the relationship between antibody to specific Opa and the risk of gonococcal salpingitis. The results are shown in Table II. Antibody to all but one of the Opa molecular weight variants showed some reduction in risk of salpingitis, although statistically significant reductions in risk were only found with antibody to the $1 \mathrm{~B}-530.0-\mathrm{kD}$ and $1 \mathrm{~A}-630.5 \mathrm{kD}$ Opa molecular variants.

The proportion of gonococcal infections resulting in salpingitis and the relative risk of salpingitis per gonococcal infection are shown in relationship to antibody to increasing numbers of Opa variants (Fig. 3). The risk of salpingitis per episode of gonococcal infection was reduced with antibody to increasing number of Opa variants. There was a stepwise reduction in the proportion of gonococcal infections with salpingitis and the relative risk of gonococcal salpingitis with increasing antibody to Opa variants. The relative risk for antibody to 7-9 Opa variants was 0.28 compared with women with antibody to $0-3 \mathrm{Opa}$ variants $(95 \% \mathrm{CI}, 0.16-0.5 ; P<0.001)$, and $0.86(95 \% \mathrm{CI}$, $0.62-1.2 ; P=0.42$ ) for antibody to $4-6$ Opa variants compared with antibody to 0-3 Opa variants. Comparing the extremes of frequency of antibody to Opa variants, the relative risk of salpingitis per episode of gonococcal cervical infection was reduced almost 10 -fold in women with antibody to all nine Opa variants compared with women with antibody to 0 and $1 \mathrm{Opa}$ variants (RR, $0.13 ; 95 \% \mathrm{CI}, 0.02-0.91 ; P<0.01)$.
30 women had more than one episode of gonococcal salpingitis. Antibodies to more Opa variants was related to reduction in the risk of recurrent gonococcal salpingitis. The relative risk of more than one episode of gonococcal salpingitis was 0.61 (95\% CI, 0.3-1.2) and 0.09 (95\% CI, 0.01-0.65) for 4-6 and 7-9 antibodies to Opa variants compared with 0-3 antibodies to Opa variants, respectively.

In examining the relationship of antibody to Opa variants and other identified or potential risk factors for gonococcal salpingitis and potential confounders, we found no relationship between antibody to 0-3, 4-6, and 7-9 Opa variants and age, the number of study visits, the duration of follow-up, the number of gonococcal infections, the number of sex partners per day, oral contraceptive use, the use of other contraceptives, and the use of condoms. There appeared to be an inverse relationship between the frequency of antibody to Opa variants and HIV-1, with 89,77 , and $65 \%$ of women with antibody to 0-3, 4-6, and 7-9 Opa variants, respectively, being HIV-1 seropositive, but this was not statistically significant $\left(P=0.76, \chi^{2}\right)$. The duration of prostitution was highly correlated with antibody to increasing number of Opa variants. The mean duration of prostitution was $36.4 \pm 40.3,39.7 \pm 35.8$, and $59.3 \pm 53.7$ mo $( \pm \mathrm{SD})$ among women with antibody to $0-3,4-6$, and 7-9 Opa variants, respectively $(P<0.004$, analysis of variance).

To assess the independent contribution of the identified 


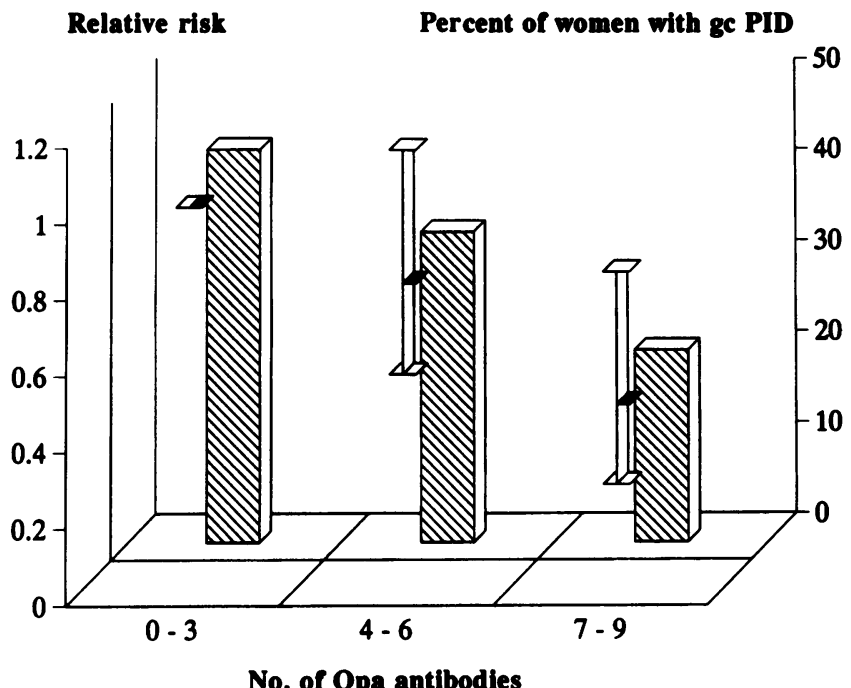

Figure 2. Antibody to Opa variants and the risk of one or more episodes of gonococcal salpingitis. The percentage of women with antibody to 0-3, 4-6, and 7-9 Opa molecular weight variants developing gonococcal salpingitis is shown in the histogram. The solid black lines indicate the relative risk of one or more episodes of gonococcal salpingitis, and the $95 \% \mathrm{CI}$ are shown with the error bars.

risk factors to the occurrence of gonococcal salpingitis, we performed a logistic regression. The results are shown in Table III. The presence of antibody to 7-9 Opa variants was strongly protective against gonococcal salpingitis (adjusted odds ratio [OR], 0.35; 95\% CI, 0.17-0.76; $P<0.001$ ). HIV infection was independently related to an increased risk of salpingitis (adjusted $\mathrm{OR}, 3.5 ; 95 \% \mathrm{CI}, 0.96-11.5 ; P<0.06)$, as were episodes of nongonococcal salpingitis (adjusted OR, 3.4; 95\% CI, 1.8$6.4 ; P<0.001$ ). As the number of gonococcal infections would influence the likelihood of gonococcal salpingitis, this variable

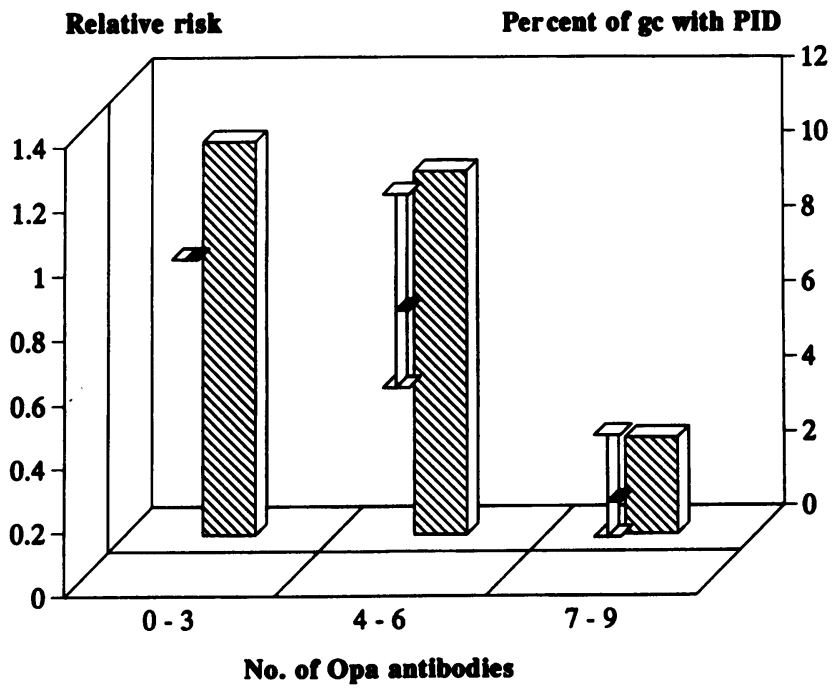

Figure 3. Antibody to Opa variants and the risk of gonococcal salpingitis per episode of gonococcal infection. The percentage of gonococcal infections resulting in salpingitis for women with antibody to 0-3, 4-6, and 7-9 Opa molecular weight variants is shown in the histogram. The solid black lines indicate the relative risk of gonococcal salpingitis per episode of gonococcal infection, and the $95 \% \mathrm{CI}$ are shown by the error bars.
Table III. Logistic Regression Analysis of Risk Factors for Gonococcal Salpingitis

\begin{tabular}{llcl}
\hline \multicolumn{1}{c}{$\begin{array}{c}\text { One or more episodes of } \\
\text { gonococcal salpingitis }\end{array}$} & $\begin{array}{c}\text { Adjusted } \\
\text { OR }\end{array}$ & $95 \%$ Cls & $P$ \\
\hline *Opa antibody & 0.35 & $0.17-0.76$ & $<0.001$ \\
HIV seropositive & 3.5 & $0.96-11.5$ & $<0.06$ \\
Nongonococcal salpingitis & 3.4 & $1.8-6.4$ & $<0.001$ \\
No. of gonococcal infections & 1.1 & $1.04-1.2$ & $<0.001$
\end{tabular}

* Antibody to seven of the nine Opa variants.

was included in the model. The number of gonococcal infections was also associated with an increased risk of salpingitis, although the increase in risk per positive culture was small (adjusted OR, 1.1; 95\% CI, 1.04-1.2; $P<0.001$ ). Age, duration of prostitution, $\mathrm{Rmp}$ antibody, condom use, and prophylactic antibiotic use were not independently related to risk of salpingitis.

As the occurrence of gonococcal salpingitis was frequently multiple, we performed a multivariate analysis for the occurrence of multiple episodes of gonococcal salpingitis using the binomial logistic model described above. In this analysis, the number of antibodies (0-9) to Opa variants was independently associated with reduced risk of salpingitis per episode of gonococcal cervicitis $(\beta, 0.1235$; se $\beta, 0.04016$; $t, 3.07$; RR, 0.88; 95\% CI, $0.81-0.96 ; P<0.001$ ). Thus, the relative risk of gonococcal salpingitis among women with antibody to all nine Opa variants was 0.28 compared with women with no antibody to Opa variants. One or more episodes of nongonococcal salpingitis was independently associated with an increased risk of salpingitis per episode of gonococcal cervicitis $(\beta, 0.2092$; se $\beta$, 0.07283; t, 2.87; RR, 1.23; 95\% CI, 1.07-1.42; $P<0.001$ ). HIV-1 infection and the number of gonococcal infections were not associated with gonococcal salpingitis in this analysis.

There were 97 episodes of nongonococcal salpingitis observed in 67 women during the study period. Nongonococcal salpingitis was related to gonococcal salpingitis (RR, 2.2; 95\% CI, 1.6-3.1; $P<0.001$ ) but inversely related to gonococcal cervicitis; the mean proportion of gonococcal cultures positive was $0.44 \pm 0.15$ among women with nongonococcal salpingitis compared with $0.54 \pm 0.23$ among women with no nongonococcal salpingitis $(P<0.01, t$ test). Nongonococcal salpingitis was unrelated to age, duration of prostitution, number of sex partners per day, condom use, contraceptive use, and HIV infection. Women with increasing numbers of antibody to Opa variants showed a somewhat reduced risk of nongonococcal salpingitis; 33, 26, and $21 \%$ of women with antibody to $0-3$, 4-6, and 7-9 Opa variants experienced one or more episodes of salpingitis. However, this trend was not statistically significant $\left(P=0.07, \chi^{2}\right.$ trend test).

\section{Discussion}

The principal finding of this study is the association of antibody to Opa with protection against gonococcal salpingitis. The frequency of antibody to the nine distinct Opa variants expressed by the five Por serovars most frequent in the gonococcal population was closely related to the likelihood of salpingitis during gonococcal infection. The relative risk of salpingitis per episode of gonococcal cervical infection was reduced al- 
most 10-fold in women with antibody to all nine Opa variants compared with women with antibody to less than one Opa (RR, $0.13 ; 95 \%$ CI, 0.02-0.96; $P<0.01$ ). There appeared to be a dose-effect relationship; the risk of gonococcal salpingitis decreased incrementally with antibody to increasing numbers of Opa variants. Although there was evidence for some reduction of the risk of salpingitis with antibody to all but one of the Opa variants expressed by the study serovars, the reduction in risk was variable and only statistically significant for antibody to two Opa variants. This again suggests that the overall protective effect observed was cumulative. The protection against salpingitis did not appear to be related to protection against gonococcal infection, as antibody to Opa variants had no effect on the frequency of gonococcal infection (11). There appeared to be no behavioral or physiologic explanations that could otherwise account for this protection. The protection also appeared to be specific, in that there was no discernable effect of Opa antibody on the occurrence of nongonococcal salpingitis. While Rmp antibody was found to increase the risk of gonococcal salpingitis, much of the increased risk appeared to be related to the increased frequency of gonococcal cervical infection, as previously reported (11). There was no effect of antibody to Por and the occurrence of gonococcal salpingitis.

Opa was initially described by Swanson et al. $(18,19)$ in relation to the colony opacity phenotype. All clinical isolates of the gonococcus express Opa $(19,20)$ and subsequent work has shown that Opa is one of the adhesins of $N$. gonorrhoeae (21, 22), mediating attachment of the organism to epithelial cell surfaces and also interbacterial adhesion. The gonococcal pilus is probably responsible for initial attachment $(23,24)$, and Opa for more close attachment (25). Opa expression has been demonstrated to confer resistance to killing by normal human sera $(26,27)$ and to enhance gonococcal killing by polymorphonuclear cell $(22,28)$. Opa undergoes both phase variation in that it may or may not be expressed by individual organisms at different times, and antigenic variation, with the repertoire of Opa variants expressed by any one gonococcal strain being diverse (29). The rates of change of Opa by individual gonococcus appears to be very rapid both in vitro and in vivo $(19,30)$. A single gonococcus may possess as many as 11 or 12 distinct opa genes that are constituitively transcribed, expression being regulated at transcription (31-33). The number of different Opa expressed by a given gonococcus is limited by the number of opa genes. However, there is evidence that the repertoire of hypervariable and immunodominant domains of Opa is more limited than the overall number of opa genes $(31,34)$. Six unique gene sequences from both the first and second opa hypervariable regions have been identified and these sequences appear to widely distributed among gonococcal strains $(31,34)$. The diversity of Opa and the genetic energy invested in it by the organism suggests that it is an important determinant of persistence of the gonococcus in its niche in the human genital tract. Phase and antigenic variation of Opa may be mechanisms whereby an individual organism evades developing host immune defenses to a component of the organism critical to the infectious process $(24,35)$. These phenomena may be of importance to the ecology of the organism, in that by prolonging infection, they increase the probability of transmission to new susceptibles.

Opa increasingly appears to be important in the pathogenesis of disease from gonococcal infection. Opa is necessary for endocytosis of the gonococcal cell by eukaryotic cells (36).
Escherichia coli expressing gonococcal Opa have also been found to invade cervical and endometrial cell lines (37). This may have relevance in the pathogenesis of gonococcal salpingitis. In a fallopian tube model of gonococcal salpingitis, transcellular migration of gonococci with the establishment of infection in the lamina propria has been observed (38). Perhaps the organism adopts this strategy to avoid host defences or in a quest for limited nutrients, such as iron. More recently specific Opa have been shown to mediate gonococcal attachment to fallopian tube tissue and mucosal damage (39).

The mechanism by which antibody to Opa reduces the risk of gonococcal salpingitis is not clear from this study, although the resistance to gonococcal salpingitis conferred by antibody to Opa suggests that Opa is a key determinant in the induction of gonococcal upper genital tract infection. Perhaps an adherence process or endocytosis mediated by Opa results in the establishment of salpingitis, the sequence of events being gonococcal adherence to the fallopian tube mucosa, endocytosis, transcellular migration, and finally establishment of infection in the submucosa. If this model is correct, antibody to Opa variants could interfere in the pathogenetic pathway of gonococcal salpingitis by preventing the occurrence of transmucosal spread of the gonococcus. As a role of antibody to Opa in mediating killing of gonococci has been described $(26,27)$, another potential explanation is that antibody to Opa participates in the killing of $N$. gonorrhoeae in the upper genital tract.

The known antigenic diversity, Opa together with the stepwise increase in protection against gonococcal salpingitis observed with antibodies to greater number of Opa variants, suggests that the protection is derived from antibody directed at surface-exposed variable domains of Opa that are known to immunodominant $(40,41)$. There is no evidence in this study that antibody to a common epitope mediates the observed protection. However, this model does not accord well with in vitro studies. Different Opa appear to mediate adherence to different cell types. The recent work by Weel et al. (36) indicated that only one of the initially many Opa types was expressed by intracellular organisms. The authors hypothesized that perhaps only certain Opa types can mediate the attachment or induce the endocytosis required for cellular penetration. If this hypothesis is correct, an alternative interpretation of our study may be that the increased protection observed with increasing numbers of antibody to Opa subtypes indicates that with greater experience with gonococcal strains, there is an increased likelihood of developing antibody to one or a few Opa subtypes that mediate cellular penetration.

Opa has been previously linked to gonococcal salpingitis (42). Gonococcal isolates from the upper genital tract of women less frequently express Opa than those from the lower genital tract. This seemingly contradicts the most likely mechanism whereby antibody to Opa acts to protect against salpingitis. Perhaps after the establishment of infection in the submucosa, the expression of Opa is no longer necessary. Alternatively, if the protection observed in this study is mediated through a bactericidal mechanism and antibody to Opa develops during gonococcal infection, perhaps strains that do not express Opa and ascend the genital tract by other means are selected.

The absence of any discernible effect of antibody to Opa variants and the risk of gonococcal cervical infection implies that Opa-mediated adherence and endocytosis are not essential for the establishment of infection. The process of the initial 
establishment of infection may be mediated by other ligands such as pilus.

The other risk factors for gonococcal salpingitis identified in this study were younger age, a shorter duration of prostitution, and HIV infection. Young age and duration of prostitution appeared to be related to the frequency of antibody to Opa variants and may reflect the accumulated exposure to gonococcal strains and immunologic experience with Opa variants. This is supported by the strong association of the frequency of antibody to Opa variants and the duration of prostitution.

HIV infection has been reported as a risk factor for salpingitis in the past $(43,44)$ but not in prospective studies. In this study, women who were initially HIV seropositive or who seroconverted during follow-up were at higher risk of gonococcal salpingitis (adjusted OR of one or more episodes, $4.2 ; 95 \% \mathrm{CI}$, $1.2-14.8 ; P<0.05)$. It seems likely that HIV infection acts to increase the risk of gonococcal salpingitis by its effects on the immune system. There was an inverse correlation between the repertoire of antibody to Opa variants and HIV infection. One mechanism whereby HIV may exert its effect on the occurrence of gonococcal salpingitis may be a reduction in the acquisition of antibody to Opa variants. Gonococcal infection may be added to the list of infections that are more frequent or more severe in the presence of HIV infection.

The strong association of gonococcal salpingitis with nongonococcal salpingitis is interesting. The strength of the association suggest that salpingitis from which $N$. gonorrhoeae was not isolated is either caused by $N$. gonorrhoeae or that common risk factors (which were not identified in this study) cause both gonococcal and nongonococcal salpingitis. If the former is true, then nongonococcal salpingitis may represent a sequela of gonococcal salpingitis. If the latter is true, then the risk factors for Chlamydia trachomatis salpingitis, the most likely bacterial cause of nongonococcal salpingitis, and gonococcal salpingitis are quite similar. Continuing studies of this population are now examining the epidemiology and biology of $C$. trachomatis salpingitis.

The generalizability of these results deserve some comment. While prostitutes are probably not representative of all women, there are several advantages of studying this particular population of women. The population is relatively homogeneous (ethnically and demographically), resides in a geographically distinct location (minimizing any effect of gonococcal strain prevalence on the frequency of salpingitis), and has very high prevalence and incidence rates of common sexually transmitted infections. All women sell sex, which minimizes the effect of differences of sexual behavior in determining risk of sexually transmitted diseases. Finally, because infections with $N$. gonorrhoeae are frequent, the effect of determinants of complications such as salpingitis may be more readily observed.

Gonococcal infection remains an important human pathogen, accounting for a large proportion of the morbidity and mortality (through ectopic pregnancy) experienced by women of reproductive age in developing countries. Control of gonococcal infection by traditional public health strategies in developing countries is a complex and long term undertaking. The development of new control measures, such as vaccines, would greatly ease the control of gonococcal infection. If this is not possible, vaccines to control some of the major adverse outcomes of gonococcal infection, such as salpingitis and its consequences, are potentially attractive. If further work confirms that antibody to Opa protects against gonococcal salpingitis, this suggests that the possibility of Opa-based vaccines should be explored.

\section{Acknowledgments}

We thank Dr. Milan Blake for the kind gift of monoclonal antibody to Opa and for his interest in the project, and Dr. Peter Rice for his advice.

This work was supported by grants from the Medical Research Council of Canada (SP27) and an STD-Cooperative Research Center grant from the National Institute of Allergy and Infectious Diseases (955765). Dr. Plummer is the recipient of a scientist award from the Medical Research Council of Canada. Dr. Simonsen was the recipient of a centennial fellowship from the Medical Research Council of Canada.

\section{References}

1. Brunham, R. C., G. P. Garnett, J. Swinton, and R. M. Anderson. 1992. Gonococcal infection and infertility in sub-Saharan Africa. Proc. R. Soc. Lond. Biol. Sci. 246:173-177.

2. Over, M., and P. Piot. 1992. HIV infection and STD. In Disease Control Priorities in Developing Countries. D. T. Jamison, and W. H. Mosley, editors. Oxford University Press, New York. In press.

3. Westrom, L. 1974. Effect of acute pelvic inflammatory disease on infertility. Am. J. Obstet. Gynecol. 121:707-713.

4. Grimes, D. A. 1986. Deaths due to sexually transmitted diseases. The forgotten component of reproductive mortality. J. Am. Med. Assoc. 255:17271729.

5. Aral S. O., W. D. Mosher, and W. Cates. 1991. Self-reported pelvic inflammatory disease in the United States, 1988. J. Am. Med. Assoc. 266:2570-2573.

6. Rice, P. A., W. M. McCormack, and D. L. Kasper. 1980. Natural serum bactericidal activity against Neisseria gonorrhoeae isolates from disseminated, locally invasive, and uncomplicated disease. J. Immunol. 124:2105-2109.

7. Wolner-Hanssen, P., D. A. Eschenbach, J. Paavonen, C. E. Stevens, N. B. Kiviat, C. Critchlow, T. DeRouen, L. Koutsky, and K. K. Holmes. 1990. Association between vaginal douching and acute pelvic inflammatory disease. J. Am. Med. Assoc. 263:1936-1941.

8. Eschenbach, D. A., J. P. Harnisch, and K. K. Holmes. 1977. Pathogenesis of acute pelvic inflammatory disease: Role of contraception and other risk factors. Am. J. Obstet. Gynecol. 128:838-850.

9. Buchanan, T. N., D. A. Eschenbach, J. S. Knapp, and K. K. Holmes. 1980. Gonococcal salpingitis is less likely to recur with Neisseria gonorrhoeae of the same principal outer membrane protein (POMP) antigenic type. Am. J. Obstet. Gynecol. 138:978-984.

10. Plummer, F. A., J. N. Simonsen, H. Chubb, L. Slaney, J. Kimata, M. Bosire, J. O. Ndinya-Achola, and E. N. Ngugi. 1989. Epidemiologic evidence for the development of serovar specific immunity after infection. J. Clin. Invest. 83:1472-1476.

11. Plummer, F. A., H. Chubb, J. N. Simonsen, M. Bosire, L. Slaney, I. W. MacLean, J. O. Ndinya-Achola, P. Waiyaki, and R. C. Brunham. 1992. Antibody to Rmp (outer membrane protein 3 ) increases susceptibility to gonococcal infection. J. Clin. Invest. 91:339-343.

12. Knapp, J. S., M. R. Tam, R. C. Nowinski, K. K. Holmes, and E. Sandstrom. 1984. Serological classification of Neisseria gonorrhoeae with use of monoclonal antibodies to gonococcal outer membrane protein I. J. Infect. Dis. 150:4448.

13. Laemmli, U. K. 1970. Cleavage of structural proteins during the assembly of bacteriophage T4. Nature (Lond.). 227:680-685.

14. Towbin, H., T. Staehelin, and J. Gordon. 1979. Electrophoretic transfer of proteins from polyacrylamide gels to nitrocellulose sheets: procedure and some applications. Proc. Natl. Acad. Sci. USA. 76:4350-4354.

15. Harlow, E., and D. Lare. 1988. Antibodies: A Laboratory Manual. Cold Spring Harbor Laboratory, Cold Spring Harbor, NY. 726 pp.

16. Breslow, N. E., and N. E. Day. 1987. Statistical Methods in Cancer Research. Vol. II. The Design and Analysis of Cohort Studies. World Health Organization, International Agency for Research on Cancer (IARC) Monographs, Lyon. 430 pp.

17. Ngugi, E. N., F. A. Plummer, J. N. Simonsen, D. W. Cameron, M. Bosire, S. Wanjiku, A. R. Ronald, J. O. Ndinya-Achola. 1988. Prevention of HIV transmission in Africa: the effectiveness of condom promotion and health education among high risk prostitutes. Lancet. ii:887-890.

18. James, J. F., and J. S. Swanson. 1978. Studies on gonococcus infection XIII. Occurrence of color/opacity colonial variants in clinical cultures. Infect. Immunity. 19:332-340.

19. Swanson, J., O. Barrero, J. Sola, and J. Boslego. 1988. Expression of outer membrane protein II by gonococci in experimental gonorrhea. J. Exp. Med. 168:2121-2129. 
20. Ison, C. A. H. L. Crabtree, C. J. Lammel, and G. F. Brooks. 1990. Expression of protein II by clinical isolates of Neisseria gonorrhoeae. In Neisseria 1990. M. Achtman, P. Kohl, C. Marchal, G. Morelli, A. Seiler, and B. Thiesen, editors. Proceedings of the Seventh International Pathogenic Neisseria Conference. Walter de Gruyter, Berlin. 597-602.

21. King, G. J., and J. Swanson. 1978. Studies on gonococcus infection. XV. Identification of surface proteins of Neisseria gonorrhoeae correlated with leukocyte association. Infect. Immun. 21:575-584.

22. Fischer, S. H., and R. F. Rest. 1988. Gonococci possessing only specific P.II outer membrane proteins stimulate adherence to human neutrophils. Infect. Immun. 56:1574-1579.

23. Buchanan, T. M., W. A. Pearce, and K. C. S. Chen. 1978. Attachment of Neisseria gonorrhoeae pili to human cells and investigations of the chemical nature of the receptor for gonococcal pili. In Immunobiology of Neisseria gonorrhoeae. F. Brooks, E. C. Gotschlich, K. K. Holmes, W. D. Sawyer, and F. E. Young, editors. American Society of Microbiology, Washington, DC. 242-249.

24. Blake, M. S. 1985. Functions of the outer membrane proteins of Neisseria gonorrhoeae. In The Pathogenesis of Bacterial Infections. G. G. Jackson, and H. Thomas, editors. Springer-Verlag, Berlin. 51-66.

25. Meyer, T. F., and J. P. M. van Putten. 1989. Genetic mechanisms and biologic implications of phase variation in pathogenic Neisseriae. Clin. Microbiol. Rev. 2(Suppl.):S139-S145.

26. Lambden, P. R., J. E. Heckels, L. T. James, and P. J. Watt. 1979. Variations in the surface protein composition associated with virulence properties in opacity types of Neisseria gonorrhoeae. J. Gen. Microbiol. 114:305-312.

27. James, J. F., E. Zurlinden, C. J. Lammel, and G. F. Brooks. 1982. Relation of protein I and colony opacity to serum killing of Neisseria gonorrhoeae. J. Infect. Dis. 145:37-44.

28. Virji, M., and J. E. Heckels. 1986. The effect of protein II and pili on the interaction of Neisseria gonorrhoeae with human polymorphonuclear leukocytes. J. Gen. Microbiol. 132:503-512.

29. Barritt, D. S., R. S. Schwalbe, D. G. Klapper, and J. G. Cannon. 1987. Antigenic and structural differences among six proteins II expressed by a single strain of Neisseria gonorrhoeae. Infect. Immun. 55:2026-2031.

30. Meyer, L. W. 1982. Rates of in vitro changes in gonococcal colony opacity phenotypes. Infect. Immun. 37:481-485.

31. Connell, T. D., D. Shaffer, and J. G. Cannon. 1990. Characterization of the repertoire of hypervariable regions in the protein II (opa) gene family of Neisseria gonorrhoeae. Mol. Microbiol. 4:439-449.

32. Bhat, K. S., C. P. Gibbs, O. Barrera, J. G. Morrison, F. J̈ahnig, A. Stern, E.-M. Kupsch, T. F. Meyer, and J. Swanson. 1991. The opacity proteins of Neis- seria gonorrhoeae strain MS11 are encoded by a family of 11 complete genes. Mol. Microbiol. 5:1889-1901.

33. Stern, A., M. Brown, P. Nickel, and T. F. Meyer. 1986. Opacity genes in Neisseria gonorrhoeae: control of phase and antigenic variation. Cell. 47:61-71.

34. Brooks, G. F., L. Olinger, C. J. Lammel, K. S. Bhat, C. A. Cavello, M. L. Palmer, J. S. Knapp, and R. S. Stephens. 1991. Prevalence of gene sequences coding for the hypervariable regions of Opa (protein II) in Neisseria gonorrhoeae. Mol. Microbiol. 5:3063-3072.

35. Shafer, W. M., and R. F. Rest. 1989. Interaction of gonococci with phagocytic cells. Annu. Rev. Microbiol. 43:121-145.

36. Weel, J. F., C. T. P. Hopman, and J. P. M. van Putten. 1991. In situ expression and localization of Neisseria gonorrhoeae opacity proteins in infected epithelial cells: apparent role of Opa proteins in cellular invasion. J. Exp. Med. 173:1395-1405

37. Simon, D., and R. F. Rest. 1992. Escherichia coli expressing Neisseria gonorrhoeae opacity-associated outer membrane protein invade cervical and endometrial epithelial cell lines. Proc. Natl. Acad. Sci. USA. 89:5512-5516.

38. McGee, Z. A., A. P. Johnson, and D. Taylor-Robinson. 1981. Pathogenic mechanisms of Neisseria gonorrhoeae: observations on damage to human fallopian tubes in organ culture by gonococci of colony type 1 or type 4. J. Infect. Dis. 143:413-422.

39. Dekker, N. P., C. J. Lammel, R. E. Mandrell, and G. F. Brooks. 1990. Opa (protein II) influences gonococcal organization in colonies, surface appearance, size and attachment to human fallopian tube tissues. Microb. Pathog. 9:19-31.

40. Zak, K., J.-L. Diaz, D. Jackson, and J. E. Heckels. 1984. Antigenic variation during infection with Neisseria gonorrhoeae. detection of antibodies to surface proteins in sera of patients with gonorrhea. J. Infect. Dis. 149:166-174.

41. Lammel, C. J., R. S. Sweet, P. A. Rice, J. S. Knapp, G. K. Schoolnik, D. C. Heilbron, and G. F. Brooks. 1985. Antibody-antigen specificity in the immune response to infection with Neisseria gonorrhoeae. J. Infect. Dis. 152:990-1001.

42. Draper, D. L., J. F. James, G. F. Brooks, and R. L. Sweet. 1980. Comparison of virulence markers of peritoneal and fallopian tube isolates with endocervical Neisseria gonorrhoeae isolates from women with salpingitis. Infect. Immun. 27:882-88.

43. Safrin, S., B. J. Dattel, L. Hauer, and R. L. Sweet. 1990. Seroprevalence and epidemiologic correlates of human immunodeficiency virus infection in women with acute pelvic inflammatory disease. Obstet. Gynecol. 75:666-670.

44. Hoegsberg, B., O. Abulafia, A. Sedlis, J. Feldman, D. DesJalais, S. Landesman, and H. Minkoff. 1990. Sexually transmitted diseases and human immunodeficiency virus infection among women with pelvic inflammatory disease. $\mathrm{Am}$. J. Obstet. Gynecol. 163:1135-1139. 